\title{
Experimental and numerical analyses of a deep foundation containing a single defective pile
}

\section{Osvaldo de Freitas Neto ${ }^{a^{*}}$ (D) , Renato Pinto da Cunhab (D), Paulo J. R. de Albuquerque ${ }^{c}$ (D), Jean Rodrigo Garciad (D), Olavo F. dos Santos Júnior ${ }^{\mathrm{a}}$ (iD)}

aDepartmento de Engenharia Civil, Universidade Federal do Rio Grande do Norte, Campus Universitário Lagoa Nova, Natal/RN, Brasil. E-mail: osvaldocivil@ufrn.edu.br, olavo@ct.ufrn.br

bDepartmento de Engenharia Civil e Ambiental, Universidade de Brasília, Campus Universitário Darcy Ribeiro, Brasília/DF, Brasil. E-mail: rpcunha@unb.br

'Departmento de Engenharia Civil e Ambiental, Universidade Estadual de Campinas, Campinas/SP, Brasil. E-mail: pjra@g.unicamp.br dDepartmento de Engenharia Civil, Universidade Federal de Uberlândia, Uberlândia/MG, Brasil. jean.garcia@ufu.br

* Corresponding author

http://dx.doi.org/10.1590/1679-78255827

\begin{abstract}
The methodologies for designing pile foundations can be complex since the simultaneous interactions among the block, piles and surrounding soil should be taken into account. Therefore, in addition to the discussions on construction, instrumentation, testing and simulation of a defective pile, this paper discusses the practical issues arising from the observed numerical using three-dimensional finite elements and experimental studies. The main issues discussed in this paper refer to as the decrease in load capacity of bored instrumented piles when subjected to a structural defect. It was observed in the results that given the presence of the defect, the failure load of the system has decreased from $190 \mathrm{kN}$ to $110 \mathrm{kN}$, i.e. around $40 \%$ reduction of the intact reference value. Using the data obtained by numerical analysis, laboratory test, and field application, it was possible that the results were satisfactory and reasonable, enhancing our understanding of this complex foundation system's behavior, especially in the presence of a defective pile.
\end{abstract}

\section{Keywords}

Bored pile, Defective piles, Loading test, Numerical analysis, instrumentation

\section{Graphical Abstract}
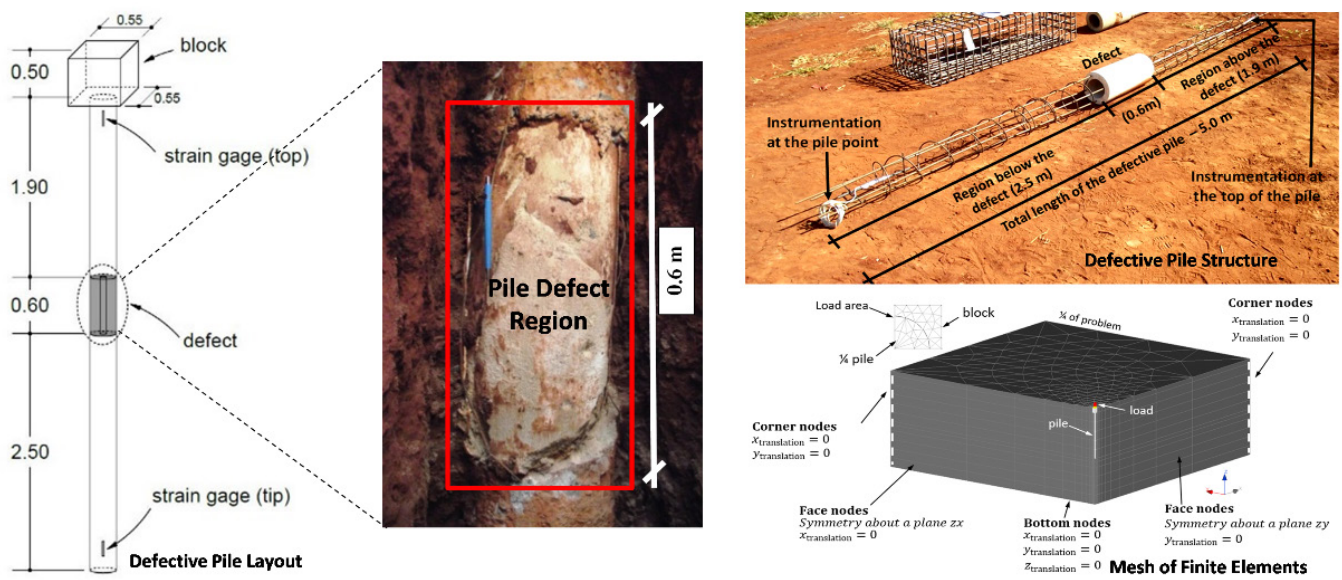

Received: October 10, 2019. In Revised Form: March 25, 2020. Accepted: April 20, 2020. Available online: April 24,2020 https://doi.org/10.1590/1679-78255827

Latin American Journal of Solids and Structures. ISSN 1679-7825. Copyright (c) 2020. This is an Open Access article distributed under the terms of the Creative Commons Attribution License, which permits unrestricted use, distribution, and reproduction in any medium, provided the original work is properly cited. 


\section{INTRODUCTION}

When a deep foundation is designed in the traditional manner, only the piles have the ability to receive and distribute superstructure loads imposed on the surrounding soils. In this case, the (positive) contribution of the pile cap is ignored, in terms of the bearing capacity, so it is assumed that the foundation behaves as a piled group. In the case of a piled block foundation, the load capacity is considered to be shared between the shallow foundation (block) and the deep foundation (piles). The present paper is related to a piled block system foundation, given that the block contribution has been taken into account and effects of interactions among different components of the foundation system (pile, soil and block) are also considered.

Unfortunately, the studies on the use of pile blocks in tropical soils are rarely reported. Besides, the studies on simulation of defected piles within piled block systems are scarce, especially for large-scale models.

A deep foundation group using the typical piled block design methodology in terms of the number and length of piles is commonly adopted. In this perspective, Freitas (2018) presents the analysis of the foundations of a wind turbine in northeastern Brazil. In this study, the author proves that when considering the foundation as a pile raft, the number of piles could be reduced from twenty-four to eight, without compromising the performance of the foundation in terms of load capacity, settlement, rotational and translational stiffness. In this way, as the number of piles under a piled block tends to be smaller than that in standard piled groups, these piles will assume greater loads in the foundation system. For this, it is important to employ an effective quality-control method during construction in order to minimize or avoid the occurrence of defective piles.

Various studies have been developed on the subject of piled blocks containing defective piles. In general, however, these studies are mainly of theoretical, numerical, or reduced-scale model studies, for example the studies of Makarchian and Poulos (1994), Abdrabbo (1997), Xu (2000), Petek et al. (2002), Kong and Zhang (2004), Novak et al. (2005), Cordeiro (2007), Cunha et al. (2007, 2010a, 2010b), Zhang and Wong (2007), Leung et al. (2010), Omeman (2012), Chung et al. (2013) and Freitas Neto et al. (2014). Experimental studies on piled blocks, particularly the full-scale testing, are rare in terms of pile defects. In this study, the behavior of a piled block with defective piles was evaluated numerically along with the built-in interaction variables. Due to the lack of information concerning the blocks and foundation groups with defective piles, the present study focused on the behavior of a full-scale block sitting on a single defective pile. The piled block was constructed at the experimental site of the College of Civil Engineering, Architecture, and Urbanism at the State University of Campinas, Brazil (FEC-Unicamp). The defective area of the pile was constituted by two types of structural defects. During the execution of the pile, a pre-cast piece with a diameter smaller than the pile diameter was installed, simulating a reduction in the cross section of the pile (necking). In addition, the defective area was made with mortar, that is, with lower mechanical properties (weakened zones), compared to the concrete that constituted the integral area of the pile. The respective defect was measured and analyzed in the laboratory prior to being installed in the field. A slow maintained load test (SMLT) was performed until structural failure occurred in the defective pile.

\section{DEFECTS IN PILED FOUNDATIONS}

Defects in piles can be of structural and/or geotechnical origin. Geotechnical defects occur due to the poor designs or insufficient geotechnical studies. Among the geotechnical defects, the most common are the base (point load) and lateral (friction) load-bearing capacities that are lower than the predicted one, in particular in presence of lenses of lowstrength materials. According to Poulos (2005), these conditions do not significantly interfere with the required loadbearing capacity, but they require elevated relative pile displacement (settlement) to mobilize them.

Defects of structural origin are generally associated with the pile execution, where it is common to occur discrepancies in dimensions, strength and/or stiffness of a pile in comparison with predict of design (Poulos, 1997). These defects usually manifest themselves as a sudden reduction in the cross-sectional area of a pile due to local concrete failures, known as necking (reduced pile cross-sectional area), weakened zones, fractured zones, and damaged zones in the pile.

The most common problems encountered in bored piles are associated concrete segregation, collapse of unprotected boreholes, pile discontinuity, or reduced cross-sectional area. In the present paper, the effects of necking and the use of material with a compressive strength and modulus of elasticity lower than those of the concrete in the pile's intact zone were selected.

Klingmüller and Kirsch (2004) presented the German perspective with regard to defective piles and showed that $15 \%$ of tested piles presented anomalies in PIT (pile integrity test) signs and $5 \%$ of the tested piles had to be denominated as defective that might require intervention. The authors have also mentioned that $30 \%$ of the defective piles showed 
problems related to concrete quality, $21 \%$ had insufficient lengths (i.e. less than those in the design), $14 \%$ showed "necking" in the shaft, and 35\% showed structural cracks.

\section{EXPERIMENTAL SITE}

The experimental site is located within the city of Campinas and covers approximately $600 \mathrm{~m}^{2}$, which consists of soils in an unsaturated and "porous", tropical condition with collapsible characteristics. The first studies on this site were performed by Gon (2011) and Scallet (2011), followed by Rodriguez (2013) and Schulze (2013), who performed geotechnical characterization tests of the area in both the laboratory and field, along with load tests on isolated piles. The results of the laboratory tests obtained by Gon (2011) are summarized in Table 1 and were used as inputs for the numerical analyses carried out herein. The soil parameters corresponding to a depth of $10 \mathrm{~m}$ were assumed as being the same as those obtained at a depth of $9 \mathrm{~m}$.

Figure 1 shows a simplified geological profile of the experimental site obtained from an in situ testing program of standard penetration test (SPT) performed by Rodriguez (2013). In Figure 1, it is observed that the SPT blow count shows little variability, perhaps as a function of the effect of suction variations. The range of results increases below $8 \mathrm{~m}$, perhaps as a function of the proximity of the rock strata which presents variable depth within the site. Scallet (2011) and Schulze (2013) performed static load tests on single piles, which have the same geometric characteristics and instrumentation as the pile tested herein. This also serves as a basis to the present analyses.

Table 1. Geotechnical parameters obtained from unsaturated compressive triaxial tests with the soil moisture content constant CW-type (modified from Gon, 2011).

\begin{tabular}{cccccccc}
\hline Depth $(\mathbf{m})$ & USCS & $\boldsymbol{v}\left(\mathbf{k N} / \mathbf{m}^{3}\right)$ & $\boldsymbol{w}(\%)$ & Suction $(\mathbf{k P a})$ & $\boldsymbol{c}(\mathbf{k P a})$ & $\boldsymbol{\varphi}\left(\mathbf{(}^{\circ}\right)$ & $E_{\mathrm{S}}(\mathrm{MPa})$ \\
\hline 1.0 & $\mathrm{MH}$ & 14.1 & 28.3 & 43.0 & 7.4 & 22.0 & 13.8 \\
2.0 & $\mathrm{ML}$ & 14.2 & 27.9 & 55.0 & 7.9 & 21.0 & 11.4 \\
3.0 & $\mathrm{ML}$ & 14.0 & 28.0 & 39.0 & 11.6 & 22.0 & 8.5 \\
4.0 & $\mathrm{ML}$ & 14.4 & 25.5 & 85.0 & 5.8 & 23.0 & 11.5 \\
5.0 & $\mathrm{ML}$ & 15.5 & 26.2 & - & 24.0 & 21.0 & 9.9 \\
6.0 & $\mathrm{ML}$ & 15.3 & 26.1 & 110.0 & 42.4 & 22.0 & 19.9 \\
7.0 & $\mathrm{ML}$ & 15.4 & 28.3 & 20.0 & 41.9 & 22.0 & 10.9 \\
8.0 & $\mathrm{MH}$ & 15.2 & 32.3 & - & 26.4 & 22.0 & 11.0 \\
$9.0-10.0$ & $\mathrm{MH}$ & 15.2 & 40.6 & - & - & - & - \\
\hline
\end{tabular}

Note: $\gamma$ is the specific weight of the soil; USCS is the unified soil classification system; $w$ is the moisture content of the soil, obtained on 20 and 21 February 2010; suction is obtained from the retention curve of the soil; $c$ is the drained soil cohesion; $\phi$ the drained internal friction angle; and $E_{s}$ the drained modulus of rigidity of the soil; ML: Low compressibility silt; MH: High compressibility silt.

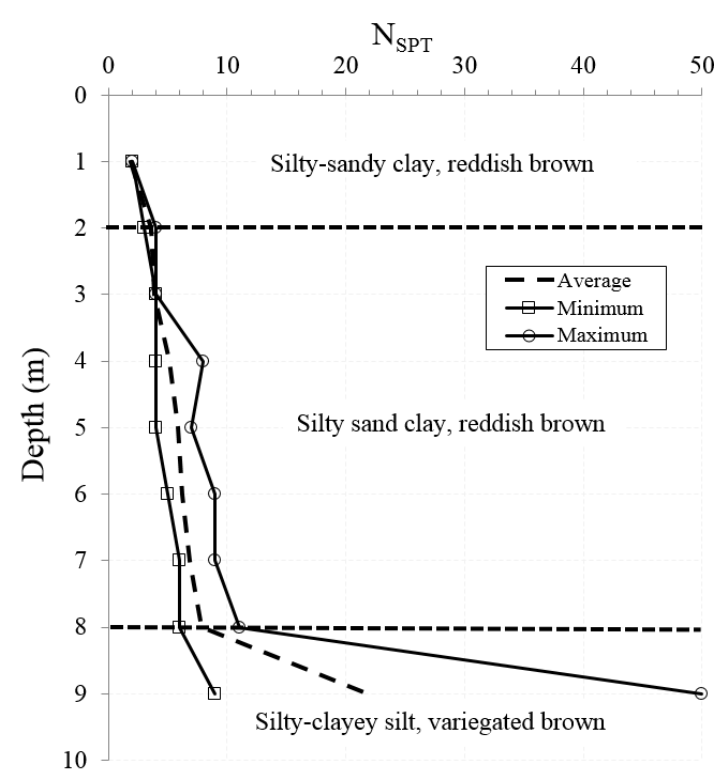

Figure 1 Simplified typical geological profile of the experimental field and summary of the standard penetration test (SPT) (modified after Rodriguez, 2013). 


\section{METHODOLOGY}

The objective of this study was to evaluate the behavior of a piled block foundation containing a defective pile, using numerical analyses such as finite element method (FEM) and experimental tests performed both in laboratory and field on a full scale. Information on the foundation's load-bearing capacity and the total settlements was obtained, either from numerical analyses or from static load tests carried out at the experimental site.

\subsection{Numerical analysis}

Numerical analyses were performed using CESAR-LCPC v. 4.07 software, developed by the Laboratoire Central des Ponts et Chaussées (Road and Public Works Research Institute). This program uses a three-dimensional (3D) numerical tool using FEM. To make the computational effort and convergence of the results compatible, a 15-noded pentahedral quadratic volumetric element was used in all the analyses.

The limits of the model were defined in order to minimize the influence of stress on the limits of the foundation. The nodes on the two lateral limits of the model are fixed against horizontal movement $(d x=0)$, but free in the vertical direction. On the other hand, the nodes at the lower limit of the model are fixed against vertical and horizontal displacements $(d x=d y=0)$. The geometry of the model was determined by means of convergence tests, which involve verifying whether the results of the boundary conditions are in accordance with the boundary limits defined in the preprocessing step.

The dimensions of the model and the respective number of nodes and elements were checked. The evaluated geometries were: $30 \mathrm{~m} \times 30 \mathrm{~m}, 40 \mathrm{~m} \times 40 \mathrm{~m}$ and $50 \mathrm{~m} \times 50 \mathrm{~m}$. The boundary conditions imposed to the problem were verified at each simulation of the validation process, in which the boundary conditions of the $50 \mathrm{~m} \times 50 \mathrm{~m}$ mesh exhibited maximum deformations less than one tenth of a millimeter, which is considered insignificant for the type of problem under analysis (Figure 2).

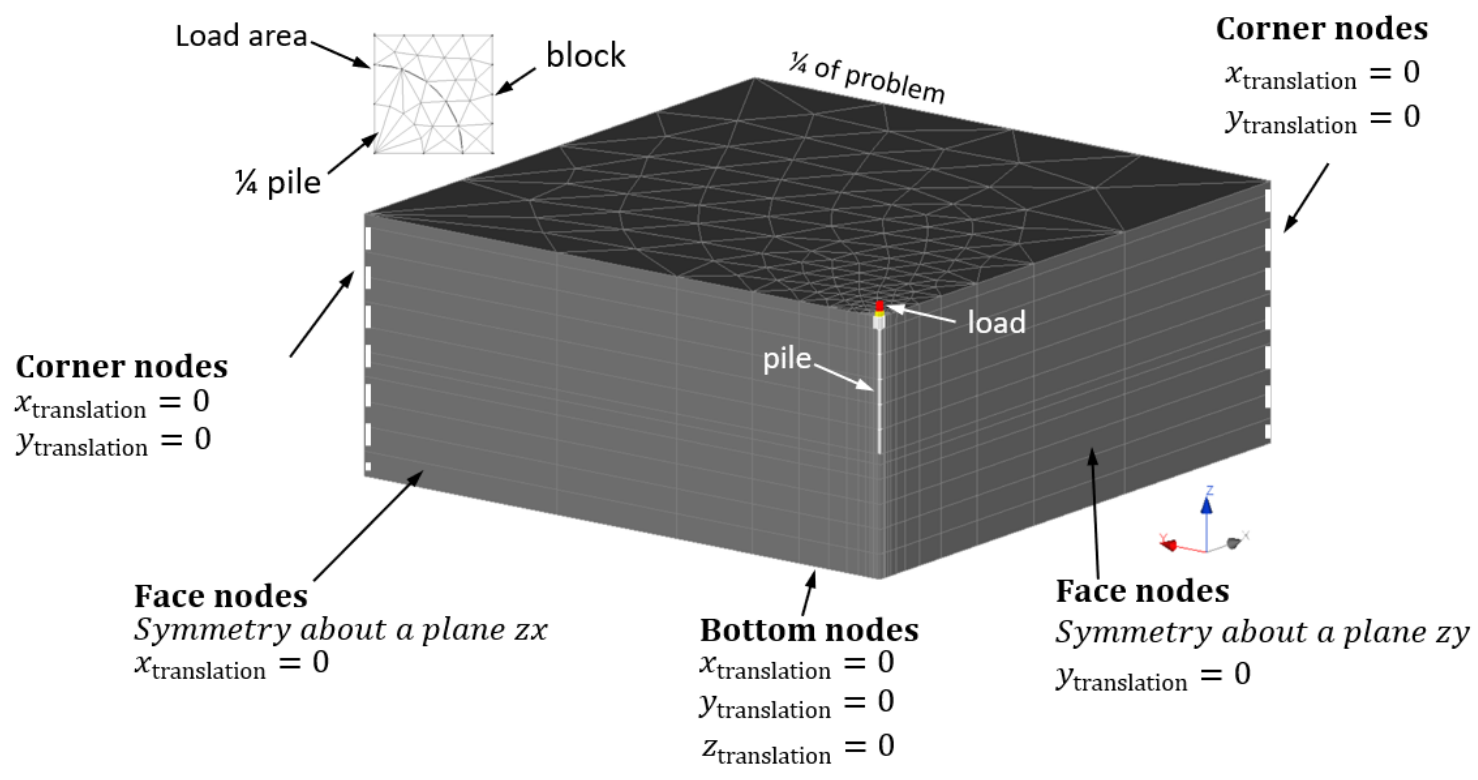

Figure 2 Boundary conditions of one quarter a symmetric 3D model.

The finite element mesh is composed of triangular elements of quadratic interpolation, which have been extruded at every meter of depth to produce a three-dimensional pentaedric element. The problem composition resulted in a finite element mesh comprising 16,116 elements and 45,860 nodes. To complement the validation analysis, refinement tests were performed on the finite element mesh to observe what changes were occurring in the maximum displacement obtained compared to other refinement conditions, with less density in terms of elements and nodes.

The refinement of the mesh, by increasing the density of the mesh in finite elements, caused the displacement initially obtained to increase in the following stages until they were practically stable in the 3rd stage. Therefore, the option was to keep the mesh with the same number of elements and nodes as in the previous phase (2nd stage), as there would be no improvement with further refinement of this mesh. 
Freitas Neto (2013) had calibrated the CESAR-LCPC software for the case studies of piled foundations available in the literature, verifying the simulations obtained from this numerical tool with the available published data. The literature results were obtained from other software tools, based on the FEM, boundary element method, and analytical method for the analysis of piled foundations.

One of the challenges to predict the behavior of foundations lies in the adequate estimation of the geotechnical parameters needed to apply constitutive models to the problem. In the present study, the geotechnical parameters was obtained from Gon (2011) CW-type triaxial tests (consolidated with constant moisture content, unsaturated), and was applied to a Mohr-Coulomb linear-elastic perfectly plastic constitutive model elastoplastic, was used to simulate the non-linear behavior of the soil in terms of stress vs strain. Soil properties assigned to the soil followed adopted failure criteria and are given by the following parameters specific weight $(\gamma)$; cohesion $(c)$; friction angle $(\phi)$; modulus of elasticity $(E)$ and Poisson's ratio $(v)$. The Plastic Parabolic model, offered by the CESAR-LCPC software, was adopted for materials with a fragile behavior (Parabolic Model) such as concrete from piles and raft, laboratory-determined and attributed for compression strength $\left(R_{c}\right)$, $E_{c}$ and $v_{c}$, and values for tensile strength $\left(R_{t}=10 \% \cdot R_{c}\right)$ and $\nu_{c}$ were adopted. It was used to model the piles given the necessity to simulate their structural failure at a given load stage.

The numerical analyses were divided into three stages. The first stage consisted of performing convergence tests where the vertical and horizontal domains were established for the interest. These domains were two and three times the length of the pile, respectively, for the aforementioned directions. Moreover, the level of refinement of the finite element mesh was established in this stage. This level was considered ideal when the convergence was reached for the structural pile elements, in terms of displacement and load distribution results. The second stage corresponded to the calibration of geotechnical parameters in the Mohr-Coulomb constitutive model, followed by the acquisition of parameters for dimensioning and molding the defective (structural) zone in the pile. The third stage involved a group of numerical analyses performed to simulate an intact piled block, as a reference system to compare the behavior of the experimental piled block with that of the defective pile loaded in the field.

Based on the aforementioned numerical analyses, it was observed that the geotechnical parameters obtained by Gon (2011), shown in Table 1, are similar to that obtained experimentally in the load tests on an isolated pile performed by Scallet (2011) and Schulze (2013) (Figure 3). The Figure 3 also shows the results from the numerical simulation carried out by Freitas Neto (2013) with the CESAR-LCPC software. Because these piles had the same geometric characteristics $(L=5 \mathrm{~m}$ and $D=0.25 \mathrm{~m})$ and were executed on the same experimental site in which was used for the present study, the geotechnical parameters obtained by Gon (2011) were used in all the numerical analyses herein.

\subsubsection{Calibration of geotechnical parameters and dimensioning of the defect}

According to Hachich et al. (1998), the ultimate capacity of a foundation can be called a "physical" failure when the relationship between the increment of the pile's settlement and the incremental load tends to approach infinity. Otherwise, such failure is referred to as "conventional", based on a criterion applied when there is no obvious physical failure of the foundation. Various criteria exist for determining the conventional failure load. The criteria proposed by Décourt (1993, 1995), and the British standard (BS 8004:1986, 1986) were adopted in order to determine the conventional ultimate capacity in this study. These criteria indicate that the defined failure load for displacement piles and bored piles must be equivalent to a settlement corresponding to $10 \%$ of the nominal pile diameter. In the present paper, the piles had a diameter of $25 \mathrm{~cm}$, thus the defined (geotechnical) ultimate load capacity was equivalent to a settlement of $25 \mathrm{~mm}(=10 \% \times 25 \mathrm{~cm})$. When applying these criteria to the load vs. settlement curves obtained by Scallet (2011) and Schulze (2013), the defined failure loads were equal to $150 \mathrm{kN}$ and 175 kN, respectively (see Figure 3).

Figure 3 also shows a defined geotechnical ultimate load capacity equivalent to $25 \mathrm{~mm}$ settlement obtained from the load vs. settlement curve in the numerical FEM analysis, performed by Freitas Neto (2013), which in this case was equal to approximately $163 \mathrm{kN}$ (Figure 3). Because the loads were reduced along the depth, variation of the axial load along the pile axis (Figure 4) was also determined from the numerical analyses.

The load in the section referring to the position where the defect would be inserted (varying between $1.9 \mathrm{~m}$ and $2.5 \mathrm{~m}$ of depth in the field) varied between $130 \mathrm{kN}$ and $140 \mathrm{kN}$ when the load on top of the pile measured $163 \mathrm{kN}$. The average structural compressive load corresponding to this cross-section, where the defect would be experimentally installed, was $135 \mathrm{kN}$ (Figure 4). Thus, applying a safety factor of 2 (according to Brazilian standard NBR 6122:2010), a value of $67.5 \mathrm{kN}$ was obtained, i.e. equivalent to the load mobilized at the section during the admissible, working, and geotechnical conditions. Since the idea was to have the isolated pile failing structurally at the defective zone just before it reached this admissible load, the defective section had therefore to be designed to withstand a maximum structural load of $67.5 \mathrm{kN}$. 


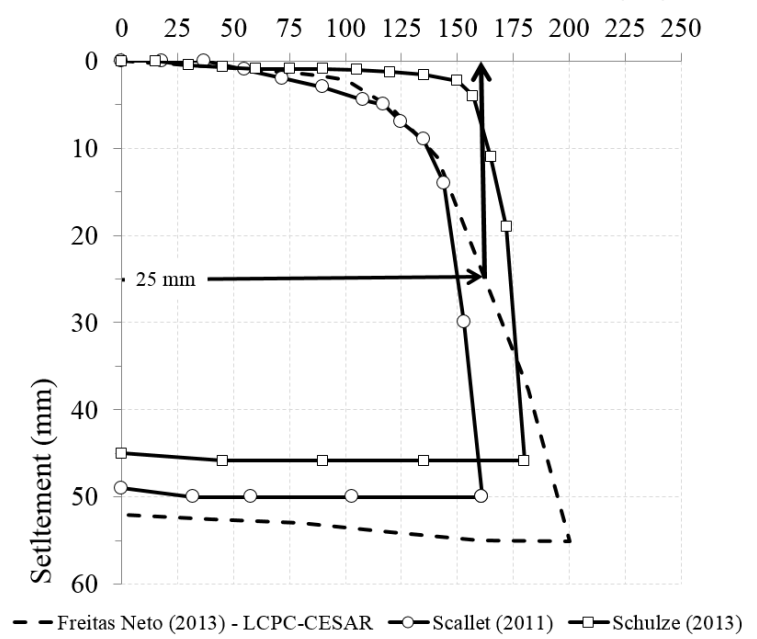

Figure 3 Numerical and experimental load vs. settlement curves of isolated intact pile (Scallet, 2011; Schulze, 2013; Freitas Neto et al., 2014).

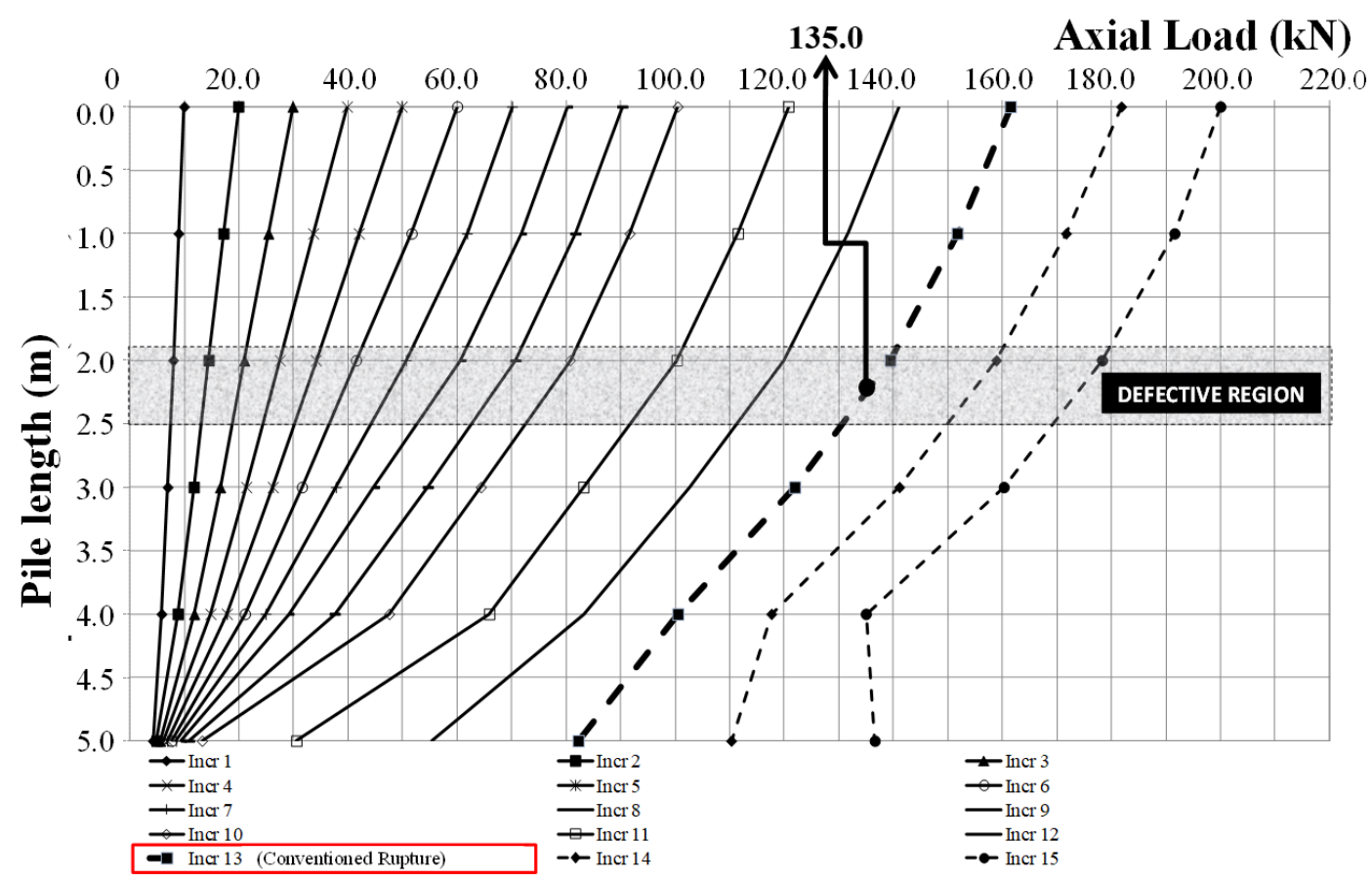

Figure 4 Numerical prediction of the compressive load along depth on the axis of the simulated isolated pile (Freitas Neto, 2013).

This numerical FEM analysis performed by Freitas Neto (2013) focused solely on the defective zone, and on the adopted back-calculated data obtained from the experimental load test conducted by Scallet (2011). Table 2 shows the geometric and elastic parameters and the load applied to the pile, used in the referenced back-analysis process. The finite element meshes adopted in model the defective pile consisted of approximately 6,000 volumetric elements and 18,000 nodes of quadratic interpolation. It should be pointed out that the vertical and horizontal domains, as well as the adopted refinement criteria, were the same as those previously discussed in Section 4.1.

Once the axial compressive load was defined at which the pile would fail during the experimental tests, it was possible to mold and simulate in the laboratory the pile's defective zone, i.e. the zone to structurally fail during tests. According to Poulos (2001), structural defects in piles can occur from cross-sections consisting of lower-quality materials, with compressive strengths and moduli of elasticity different from those of the material constituting the intact zone of the pile, and / or through a cross-sectional reduction in the pile. In this study, both characteristics were evaluated. 
Table 2. Parameters used in the numerical analysis of the experimental load test performed by Scallet (2011) (modified after Freitas Neto, 2013).

\begin{tabular}{cccccccccc}
\hline$D(\mathrm{~m})$ & $A_{\mathrm{P}}\left(\mathrm{m}^{2}\right)$ & $B(\mathrm{~m})$ & $L(\mathrm{~m})$ & $\boldsymbol{H} / L$ & $E_{\mathrm{p}}(\mathrm{GPa})$ & $\boldsymbol{k}_{\mathbf{0}}$ & $\boldsymbol{v}_{\mathrm{c}}$ & $\boldsymbol{v}_{\mathrm{s}}$ & $\boldsymbol{P}_{\max }(\mathrm{kN})$ \\
\hline 0.25 & 0.0491 & $3 . \mathrm{L}$ & 5 & 2 & 22.85 & 0.626 & 0.15 & 0.45 & 200 \\
\hline
\end{tabular}

Note: $D$ is the diameter of the pile section, $A_{\mathrm{p}}$ the cross-sectional area of the pile, $B$ the horizontal domain, $L$ the pile length, $H / L$ the vertical domain, $E_{\mathrm{p}}$ the modulus of elasticity of the pile, $k_{0}$ the thrust coefficient at rest, $v_{c}$ the Poisson's ratio of the concrete, $v_{\mathrm{s}}$ the Poisson's ratio of the soil, and $P_{\text {max }}$ the maximum load applied to the top of the pile.

The defective pile section was molded with mortar at a cement/sand $(C / S)$ ratio of 1:9 and water/cement $(W / C)$ ratio of 1.5. The ideal mixture was determined by means of an experimental laboratory study in such a manner that the optimum sand/cement ratio and water/cement ratio produced an average rupture stress of $1500 \mathrm{kPa}$. The intact cross-section of the pile had a solid diameter of $25 \mathrm{~cm}$.

To mimic the reduction of the pile cross-sectional area, a hollow cylinder with a diameter equal to $18.4 \mathrm{~cm}$ was molded, decreasing the cross-section of the intact pile by $26.4 \%$. Under these molding conditions, the full-scale specimens that simulated the pile's cross-section underwent uniaxial compressive strength tests in the laboratory, with the same dimensions and possibly similar conditions as those that would be encountered in the field. Test results are presented in Table 3. It is noted that the specimen that simulated the defective zone of the pile failed at $38.5 \mathrm{kN}$, lower than the failure load predicted by FEM analysis, representing a safety factor higher than 1.5 , which was the minimum required to guarantee a rupture in the field test, during the pile loading process. Thus, it was understood that if the defective zone of the pile was molded under such conditions and installed in the field, structural failure would actually occur before the predictions of the numerical analysis.

Table 3. Results from simple uniaxial compression tests performed on defective sections similar to those installed in the field.

\begin{tabular}{cccccccc}
\hline Material & Method & $D_{\text {ExtAVE }}(\mathbf{m})$ & $D_{\text {IntAvE }}(\mathbf{m})$ & $D_{\text {Equiv }}(\mathbf{m})$ & $\boldsymbol{P}_{\mathrm{u}}(\mathbf{k N})$ & Area $\left(\mathbf{m}^{2}\right)$ & $\sigma_{\mathrm{u}}(\mathbf{k P a})$ \\
\hline Mortar $(C / S$ & FEM prediction & 0.245 & 0.15 & 0.194 & 67.5 & 0.0295 & 2,290 \\
ratio of 1:9, and & Experiment (specimen 1) & 0.237 & 0.242 & 0.182 & 40 & 0.0259 & 1,540 \\
W/C ratio of 1.5) & Experiment (specimen 2) & 0.239 & 0.244 & 0.185 & 38.5 & 0.0270 & 1,410 \\
\hline
\end{tabular}

Note: $D_{\text {ExtAVE }}$ is the average external diameter of the defect region, $D_{\text {IntAVE }}$ the average internal diameter of the defect region, $D_{\text {EQuIV }}$ the equivalent diameter of the defect region, $P_{\mathrm{u}}$ the ultimate load capacity of the defective region, and $\sigma_{\mathrm{u}}$ the ultimate capacity of the stress defective region.

\subsubsection{Numerical analyses of the intact and defective piled block}

To obtain a model with which to compare the foundation containing a defective pile, numerical analyses were performed on the respective (idealized) block containing an intact pile. A numerical evaluation of the experimental block with defective pile was also made. The nomenclatures adopted for the numerical simulations were IPR(NUM) and DPR(NUM) for the block founded on an intact and defective pile, respectively; likewise, DPR $($ EXP) are for experimental studies. Table 4 shows the geometric and elastic parameters used in the numerical analyses. The geotechnical parameters used for all of the numerical simulations are shown in Table 1.

\subsection{Installation of the piled block and static load test}

The pile cross-section is shown in Figure 5. From this figure, it is possible to note its general layout under the block, the dimensions of the piled block, the dimensions and location of the defect, and the respective positions of the instrumentation at the top and bottom of the pile. The pile was instrumented at these locations with strain gages installed in a complete full bridge-type arrangement.

The first installation stage involved cleaning the ground and excavating the shaft to an approximate depth of $5 \mathrm{~m}$ with a borehole containing a short helical auger coupled to a telescoping stem, followed by the installation of the structural reinforcement cage and pouring of concrete. The defective pile was reinforced with 4 CA-50A steel bars $(\phi=10 \mathrm{~mm})$ and a helical stirrup of CA-50 steel $(\phi=6.5 \mathrm{~mm})$. In contrast to the defective pile, the reaction piles were reinforced along their entire length. The top block was structurally dimensioned by assuming it as a rigid element, i.e. with lines of internal compressive stresses inclined at an angle of around $40^{\circ}$ to $55^{\circ}$ to the horizontal. This procedure produced a reinforcement of $10 \mathrm{~mm}$ diameter steel bars spaced every $20 \mathrm{~mm}$. The ultimate compressive strength of the concrete for both piles and block was $25 \mathrm{MPa}$.

The installation procedure used for the defective pile differed from that of the reaction piles since, in the former case, the longitudinal reinforcement was divided into two $2.5-\mathrm{m}$ segments, and an additional $0.6 \mathrm{~m}$ segment was cut on the upper half of the reinforcement. This region taken from the reinforcement corresponded to the position at which 
the defect was installed. The defect was positioned in the upper medium segment of the pile, i.e. between depths of $1.9 \mathrm{~m}$ to $-2.5 \mathrm{~m}$ (Figure 5). This position was defined by considering that the closer the defect to the surface, the higher its influence on the foundation behavior. Figure 6 shows the longitudinal composition of the defective pile. In this case, the installation sequence followed the procedure given below:

(1) Positioning of the reinforcement in the lower region of the pile at the bottom of the borehole;

(2) Pouring of concrete for the lower 2.5-m-long region of the pile;

(3) Installation of the pre-molded, hollow mortar cylinder that represented the defective zone, or the defect itself, lowering it until it reached the previously poured region;

(4) Installation of the upper region of the pile, followed by the pouring of concrete;

(5) Preparation of the block (pile top block): excavation (Figure 7); positioning of the reinforcement (Figure 8) and concrete casting (Figure 9); and

(6) Excavation around the block to avoid lateral friction (Figure 10).

Table 4. Geometric and elastic parameters used in the numerical analyses.

\begin{tabular}{|c|c|c|c|c|c|c|c|c|c|c|c|c|c|c|c|c|c|c|}
\hline $\begin{array}{l}D_{\mathrm{Pl}} \\
\text { (m) }\end{array}$ & $\begin{array}{l}D_{\mathrm{PD}} \\
\text { (m) }\end{array}$ & $\begin{array}{c}A_{\mathrm{P} 1} \\
\left(\mathrm{~m}^{2}\right)\end{array}$ & $\begin{array}{l}A_{\mathrm{PD}} \\
\left(\mathrm{m}^{2}\right)\end{array}$ & $\begin{array}{c}B \\
\text { (m) }\end{array}$ & $\begin{array}{c}L \\
(\mathrm{~m})\end{array}$ & $\begin{array}{l}L_{\mathrm{d}} \\
(\mathrm{m})\end{array}$ & $\begin{array}{c}z_{d} \\
(m)\end{array}$ & $\begin{array}{c}R_{\mathrm{c}} \\
(\mathrm{MPa})\end{array}$ & $\begin{array}{c}R_{\mathrm{t}} \\
(\mathrm{MPa})\end{array}$ & $\sigma_{\text {applied }}$ & $H / L$ & $s / D_{\mathrm{Pl}}$ & $\begin{array}{c}E_{\mathrm{P}}=E_{\mathrm{R}} \\
(\mathrm{GPa})\end{array}$ & $\begin{array}{c}E_{\mathrm{PD}} \\
(\mathrm{GPa})\end{array}$ & $\begin{array}{c}E_{\mathrm{s}} \\
(\mathrm{MPa})\end{array}$ & $v_{c}$ & $v_{s}$ & $\begin{array}{c}t\left(\text { IPR }_{\text {(NuM) }}\right) \\
\text { and } \\
\left.\operatorname{DPR}_{(\text {Num })}\right) \\
(\mathrm{m})\end{array}$ \\
\hline 0.25 & 0.185 & 0.049 & 0.027 & $3 L$ & 5 & 0.6 & 1.90 & 25 & 2.5 & Variable & 2 & 5 & 22.9 & 5.9 & $\begin{array}{c}\text { Table } \\
1\end{array}$ & 0.2 & 0.45 & 0.55 \\
\hline
\end{tabular}

Note: $D_{P I}$ is the diameter of intact piles; DPD the equivalent diameter of the defective cross-section; ApI the cross-sectional area of the intact zone of the piles; $A_{P D}$ the cross-sectional area of the defective zone of the piles; Ld the length of the defective zone; $z d$ the depth of the defect; $t$ the block thickness; s/DPI the relative spacing; $E_{P}$ and $E_{R}$ are the moduli of elasticity of the concrete in the pile and block, respectively; $E_{P D}$ is the modulus of elasticity of the defect material; $\sigma_{\text {applied }}$ the stress applied at the center of the block; $R_{c}$ the compressive strength of the concrete; and $R_{t}$ the tensile strength of the concrete.

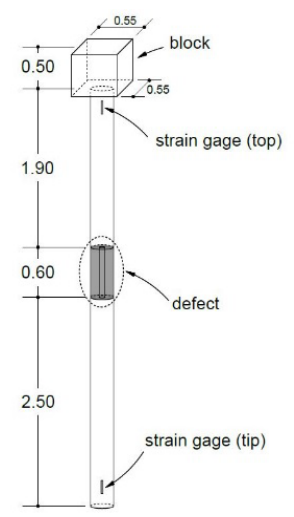

Figure 5 Schematic of the defective pile and instrumentation for $\operatorname{DPR}_{(\mathrm{EXP})}$.

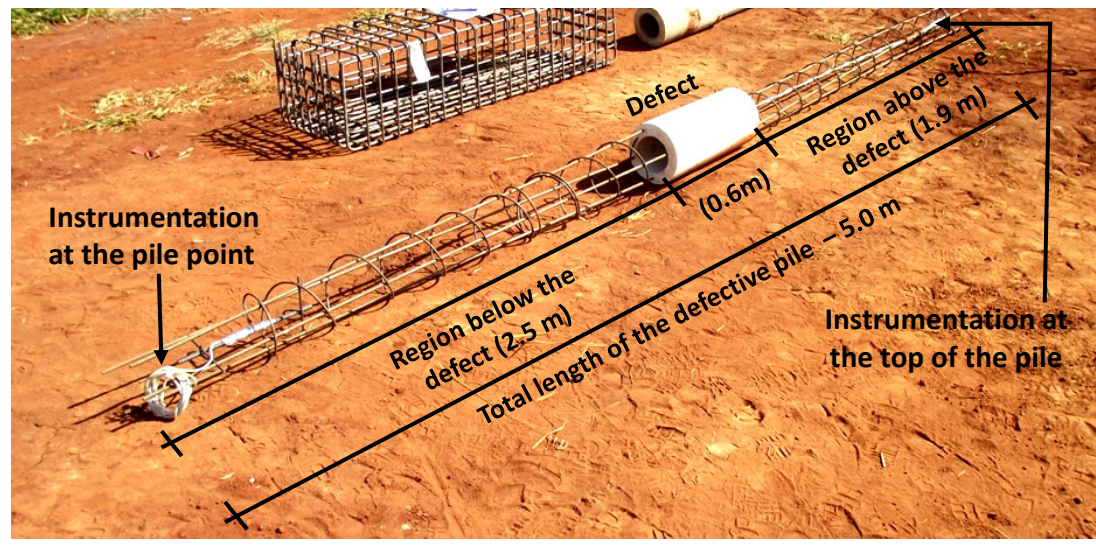

Figure 6 Longitudinal design of the defective pile (total length, size and positioning of the defective zone and placement of instrumentation). 


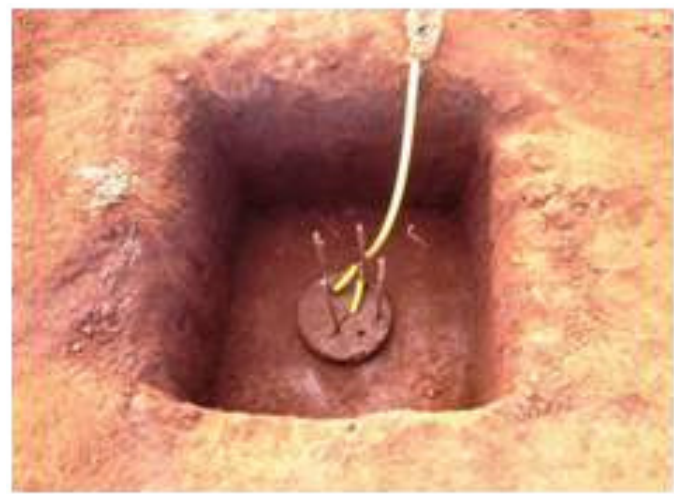

Figure 7 Excavation to the leveling mark of the pile for DPR(EXP).

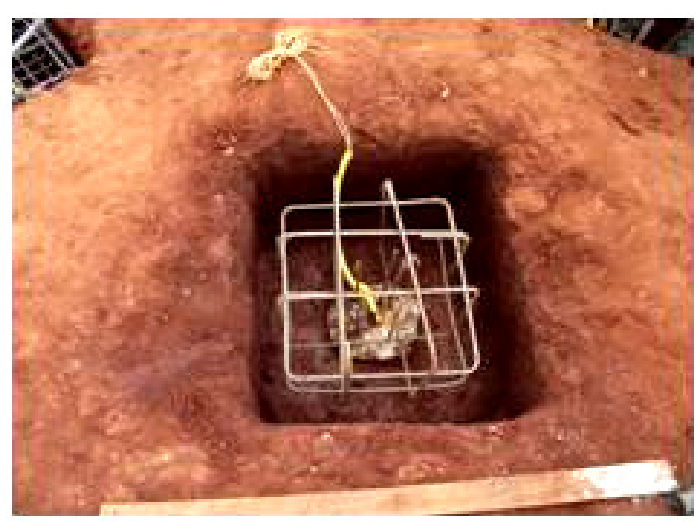

Figure 8 Positioning the reinforcement for $\mathrm{DPR}_{(\mathrm{EXP})}$.

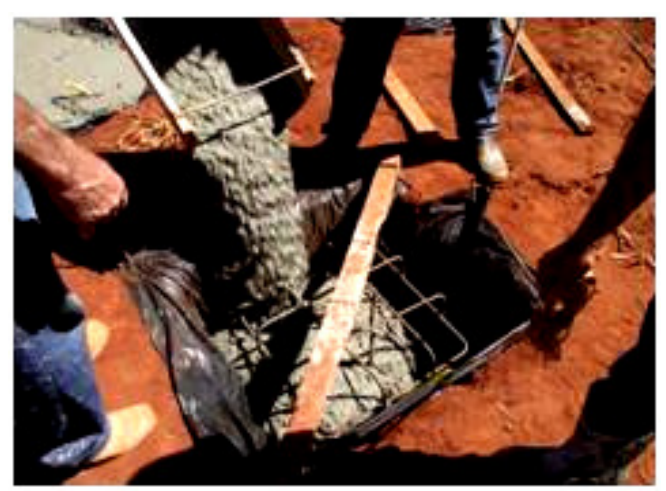

Figure 9 Pouring the concrete for $\mathrm{DPR}_{(\mathrm{EXP})}$.

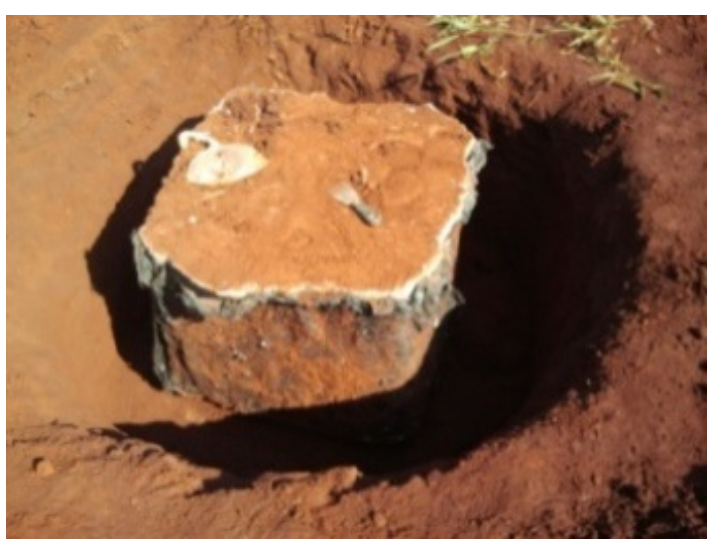

Figure $10 D P R_{(E X P)}$ system excavated laterally. 
The instrumentation (strain gages, connected in a full bridge configuration) was fixed to the axis of the reinforcement, thus positioned at the top and base of the tested pile. The encasement of the pile's reinforcement in the block was guaranteed with a $10-\mathrm{cm}$ indentation in all piles. Additionally, prior to positioning the reinforcement in the block, the instrumentation wires were duly protected by passing them through PVC tubes.

Concrete specimens were molded from each stage during the installation process. The concrete samples, molded in the field, have been subjected to uniaxial compression tests to estimate their deformation and strength properties.

The results of the compression tests are shown in Table 5 with both concrete and steel's modulus of elasticity. The composite modulus of the reinforced concrete is also shown, calculated by considering that the deformations were equal in both concrete and steel elements at the instrumentation's level, since the instrumentation bar was fully immersed in the pile's concrete. The value of this combined modulus was adopted during the interpretation of the results from the pile's instrumentation in the aforementioned static load test.

Table 5. Summary of the results obtained from the compression tests and corresponding moduli of elasticity used for interpreting the instrumentation of the pile in the $\mathrm{DPR}_{(\mathrm{EXP})}$ system.

\begin{tabular}{ccccc}
\hline Concrete & $\sigma_{\text {Rupt }}(\mathrm{MPa})$ & $E_{\text {concrete }}(\mathrm{GPa})$ & $E_{\text {Steel }}(\mathrm{GPa})$ & $E_{\text {composite }}(\mathrm{GPa})$ \\
\hline Pile in $\mathrm{DPR}_{(\mathrm{EXP})}$ system & 27.8 & 32 & 210 & 33.1 \\
\hline
\end{tabular}

Note: $\sigma_{\text {Rupt }}$ is the ultimate load capacity of concrete of the pile, $E_{\text {concrete }}$ is the modulus of elasticity of the concrete, $E_{S t e e l}$ is the modulus of elasticity of the steel, and $E_{\text {composite }}$ is the modulus of elasticity of the composite.

\subsection{Static load test}

The load test shown in this study was performed as per the Brazilian standard NBR 12131:2006 (2006). In addition to the test pile, mechanically bored type reaction piles were also installed, with dimensions of $0.6 \mathrm{~m} \times 9.0 \mathrm{~m}$ (diameter $\times$ length). These piles were designed to resist the tensile forces caused by the reaction system during the load tests and were reinforced with 10 CA-50 steel bars $(\phi=10 \mathrm{~mm}$ ) and a helical CA-50 steel stirrup ( $\phi=6.5 \mathrm{~mm})$. This reinforcement was complemented by the installation of a Dywidag type steel bar with an identical length and diameter of $32 \mathrm{~mm}$. The reaction beam used in the load tests was $5.3 \mathrm{~m}$ long and assembled by the union of two l-shaped steel profiles, the crosssection of which had flange and web of $0.32 \mathrm{~m}$ and $0.74 \mathrm{~m}$, respectively. It weighed approximately $31 \mathrm{kN}$ and had a resistance capacity of approximately $2,000 \mathrm{kN}$ (Figure 11). An ordinary load cell with the maximum capacity of $2,000 \mathrm{kN}$ was used for the load measurement devices applied to the top of the block. The displacement readings were performed using four displacement transducers (LVDT) with range of $100 \mathrm{~mm}$. These transducers were fixed on two orthogonal axes with magnetic bases and a flexible extensible arm. In this way, it was possible to obtain both the average and the differential settlement on the piled block before and after the structural pile failure (at defective zone).

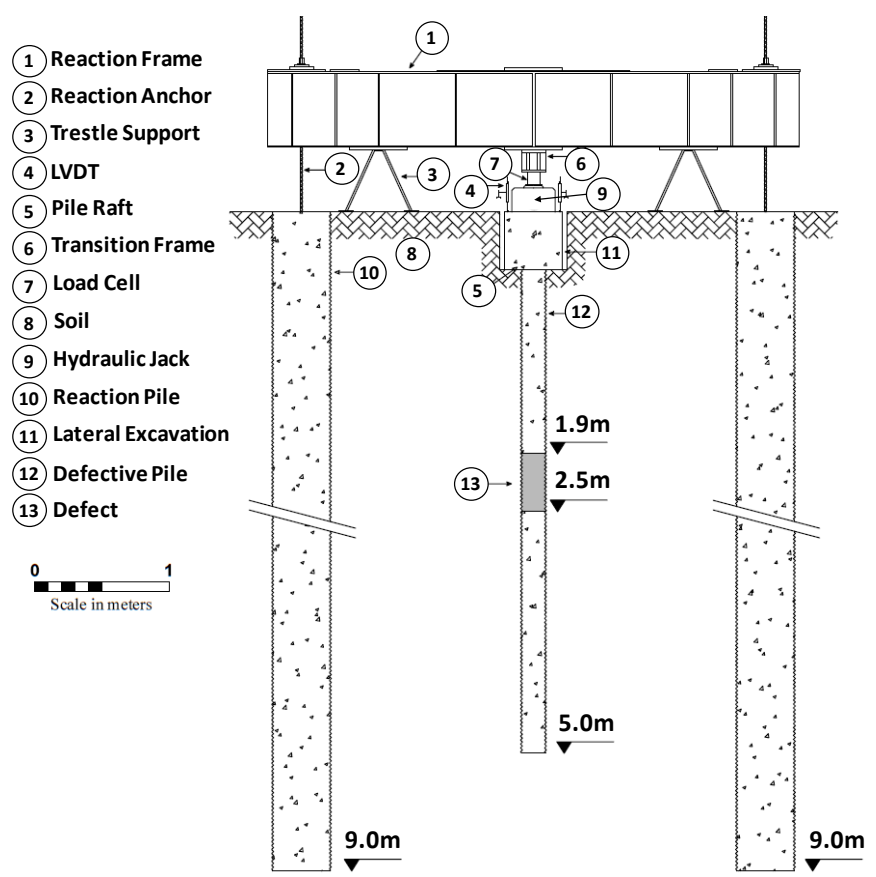

Figure 11 Front view sketch of the main reaction system (Garcia, 2015). 


\section{RESULTS AND DISCUSSION}

This section presents and discusses the experimental results obtained for the piled block founded on a single defective pile $\left(D R_{(E X P)}\right)$, via static load test, and the numerical simulations via 3D FEM modeling using CESAR-LCPC software (DPR(NUM) and IPR(NUM)). Table 6 gives the values of the defined (geotechnical) ultimate load capacity and settlement results obtained from both numerical analyses and the static load test carried out in the field. The defined (conventional) ultimate load capacity was set at $25 \mathrm{~mm}$ of settlement from the load vs. settlement curves, as previously stated.

Table 6. Summary of the results obtained from the load tests performed in the field and the numerical analyses (IPR(NUM), DPR $\left(\mathrm{NUM}_{(\mathrm{M})} \mathrm{and} \mathrm{DPR}_{(\mathrm{EXP})}\right)$.

\begin{tabular}{cccccccc}
\hline Piled block & $\boldsymbol{N}_{\mathrm{E}}$ & $\boldsymbol{N}_{\mathrm{PD}}$ & $\boldsymbol{\Delta} \boldsymbol{Q}(\mathbf{k N})$ & $\boldsymbol{P}_{\mathrm{u}}(\mathbf{k N})$ & $\boldsymbol{\rho}_{\text {MRUPT }}(\mathbf{m m})$ & $\boldsymbol{\rho}_{\text {MAX }}(\mathbf{m m})$ & $\boldsymbol{\rho}_{\text {DMAX }}(\mathbf{m m})$ \\
\hline $\mathrm{IPR}_{\text {(NUM) }}$ & 1 & 0 & 15.0 & 190.0 & 25.0 & 59.8 & - \\
$\mathrm{DPR}_{\text {(NUM) }}$ & 1 & 1 & 20.0 & 133.0 & 25.0 & 91.0 & - \\
$\mathrm{DPR}_{(\text {EXP) }}$ & 1 & 1 & 15.0 & 110.0 & 25.0 & $\sim 100.0$ & $\sim 25.6$ \\
\hline
\end{tabular}

Note: $N_{\mathrm{E}}$ is the number of piles under the block, $N_{\mathrm{PD}}$ the number of defective piles under the block, $\Delta Q$ the load increment applied at each loading stage, $P_{\mathrm{U}}$ the geotechnical ultimate load capacity of the foundation, $\rho_{\text {MRUPT }}$ the average settlement at ultimate load capacity, $\rho_{\text {MAX }}$ the maximum settlement at the end of the loading stage; and $\rho_{\mathrm{DMAX}}$ the maximum differential settlement.

Figure 12 compares the load-settlement curves obtained numerically for the simulated intact and defective piled

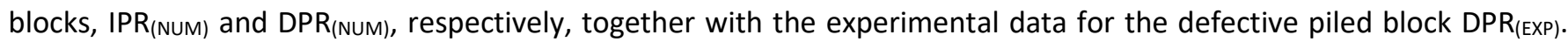
Considering only the numerical results, it is hypothesized that a block founded on an intact pile would have a conventional geotechnical failure load of $190 \mathrm{kN}$. This load was defined as the value corresponding to a $10 \%$ displacement of the pile diameter, as mentioned previously. Due to the defective pile, the failure load drops to $133 \mathrm{kN}$. Taking into account a common definition for safety factor, i.e. the ratio between the ultimate failure load (at intact condition) over the actual load, some interesting scenarios are observed. First, according to the numerical modeling of the defective pile implies an approximately $30 \%$ decrease in the pile failure load. Secondly, by developing a defective zone, the defective DPR(Num) system geotechnically fails at a safety factor of 1.4 but not 1 , as previously expected when applying the (Brazilian) design standard (allowable load at safety factor of 2). It is also noticeable that the value of $\alpha_{\mathrm{pr}}$ during failure, i.e. the division of load between the block and defective pile, was around 0.5 (50\%) for both experimental and numerical cases.

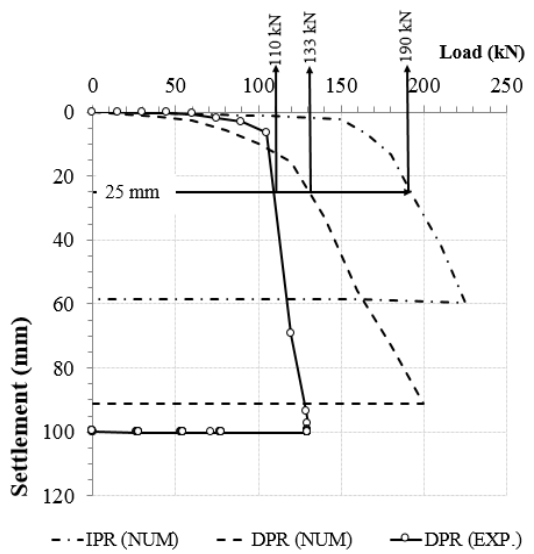

Figure 12 Comparison of the load vs. settlement curves for the distinct piled blocks either numerically simulated or experimentally tested.

Comparing the numerical and experimental results that are respectively valid for the IPR(NUM) and DPR(EXP) Systems, it can be concluded that there is a decrease of approximately $40 \%$ of the failure load of the system foundation. The defective system geotechnically fails at a safety factor of $\sim 1.7$ rather than 1 . In this latter case, if the system was designed assuming an allowable load of $95 \mathrm{kN}$ at a safety factor of 2 (based on intact IPR $(\mathrm{NUM})$ failure load), the conclusion is that if a defective zone develops, it leads this system to be at an imminent failure stage (at $110 \mathrm{kN}$, with an actual safety factor of 1.16).

By adopting the defined (conventional) load-bearing capacity value of the numerical IPR(Num) system as a benchmark, the global safety factor at each loading level was determined for both defective experimental DPR(EXP) and intact numerical IPR(NUM) systems. For instance, at $95 \mathrm{kN}$ load level, the intact system has a designed safety factor of 2, i.e. 190/95 (hence this would be the allowable working load of the system). Under the same load, the defective system has an actual (generally unknown by the designer) safety factor of 1.16, i.e. 110/95. 
As observed, the load vs. displacement behavior obtained in the numerical simulation of the defective pile did not satisfactorily represent the field performance, especially for values close to the failure load. This can be attributed to the particular characteristics of the soil next to the pile (tropical soil), and principally to the failure mode of the defective section. It should be noted that the material of the pile presents a fragile type rupture, whereas in the numerical simulation, this specific characteristic could not be employed.

One should realize that this is just an academic exercise on the comments given in previous sections of the paper, where it was stated that the defect was actually molded intentionally to "activate" itself around the admissible (geotechnical) load of the isolated pile. The installed defect in the pile was intended to simulate typical structural pathologies found in such foundation elements. To do so, it was assumed that one pile segment $0.6 \mathrm{~m}$ in length would consist of mortar, whose mechanical properties are inferior to those of the pile's concrete. The defect therefore would simulate a necking type structural failure of the pile's shaft. It was designed to present and quantify, roughly, the consequences of a defect in a piled block system. Nevertheless, the discussion clearly serves to describe how misguided one can sometimes be with the design once a hidden defect turns out to be active in the foundation. It is also obvious that, the larger the number of piles, the lower the influence of this variable on final behavior and safety standards. In fact, Freitas Neto (2013) demonstrated this with other (larger) piled block systems tested on this same site.

To check the structural failure of the pile defective zone, after the load test, a $3 \mathrm{~m}$-deep trench with a $0.9 \mathrm{~m}$ diameter was excavated next to the pile. Figures 13 and 14 confirm the structural failure hypothesis and corroborate the predictions (experimental and numerical) for the pile behavior in this particular zone along the testing stages. Indeed, it is noticeable that the defect was fully mobilized, leading to the total failure of this zone. Moreover, by comparing the overall geometric aspects of both failed zones from the laboratory and the field, the failure mechanisms of the defective zone were similar, which was concentrated along one direction of the shaft, perhaps allowing for the extreme angular distortions observed for the tested system in the post failure stage.

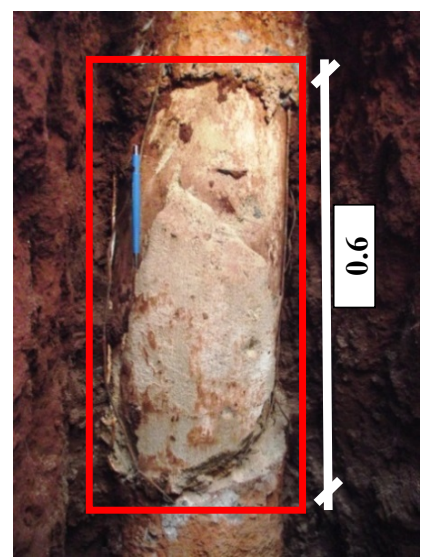

Figure 13 Defective zone in the pile mobilized after load test performed on $\operatorname{DPR}_{(\mathrm{EXP})}$ system.

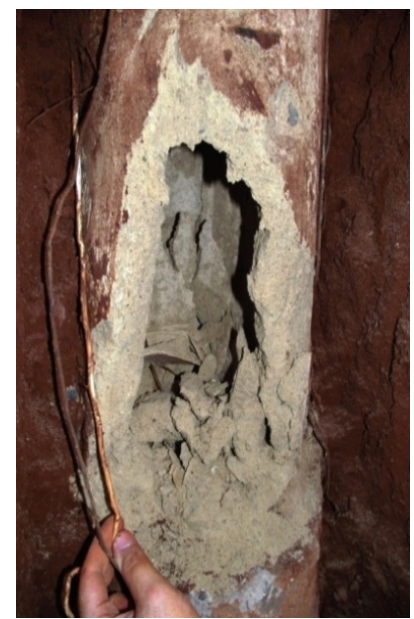

Figure 14 Another detail of the defect after load tests performed on DPR (EXP) system. 


\section{CONCLUSIONS}

The numerical modeling represented by $\mathrm{DPR}_{(\mathrm{NUM})}$ analysis, failed to simulate the behavior of the pile under the field's loading procedure DPR (EXP) analysis, especially for stages with loads higher than the workload (loads greater than $95 \mathrm{kN})$. The main reason for this was the fragile rupture of the pile in the defective zone, which resulted in the loss of bearing capacity after the element breakdown.

Once a defect is mobilized, i.e. "activated" within the pile, there is an inevitable loss of bearing capacity of the entire piled block system, and simultaneous increase in displacement for the same load level, when compared to an "intact" non-defective system. The present numerical (DPR(NUM)) and experimental (DPR (EXP) $_{(1)}$ analysis demonstrate that, for a system with a single pile (worst case scenario), the failure load can be decreased to $40 \%$ of the intact condition (IPR(NUM) analysis). In this particular case, one can also observe that the envisaged safety factor of the system (in terms of bearing capacity) is misleading in allowable design conditions. The failure load of the intact piled block was $190 \mathrm{kN}$. Assuming a safety factor of 2, the allowable load on this intact foundation would be $95 \mathrm{kN}$. Observing the results obtained both in the numerical simulation and in the load test, it was concluded that at $95 \mathrm{kN}$ the defective foundation was in the imminence of the rupture, that is, with a safety factor of close to 1 , when the expectation for such load level was that the was 2 .

In light of the above, it is therefore noticeable that detection procedures for checking possible defects, to allow for quality assurance for the piles of a foundation system, must be encouraged.

It is finally worth emphasizing that the results obtained in the present research cannot be extrapolated indiscriminately to blocks with a larger number of piles, because the geometry of a block and the number and positioning of intact and defective piles can exert significant influence on the behavior of the foundation system. Indeed, as demonstrated by Freitas Neto (2013), there seems to be a tendency to diminish the importance of the defective pile in larger piled block systems, with a higher number of piles, but further studies in this field are essential.

\section{ACKNOWLEDGMENTS}

The authors are grateful to the FAPESP (Sao Paulo Research Foundation) and company Dywidag-Systems International Ltd. for the financial aid for experimental tests kindly provided throughout this research. The first author also acknowledges the support provided by the Brazilian research sponsorship organizations CNPq (National Council for Scientific and Technological Development), Unicamp (State University of Campinas) and CAPES (Higher Education Personnel Improvement Coordination). The authors are also indebted to the Geotechnical Graduate Program of the University of Brasilia (UnB) and to the Civil Engineering Graduate Program of Federal University of Rio Grande do Norte (UFRN).

Author's Contribuitions: Conceptualization, O Freitas Neto, RP Cunha, PJR Albuquerque and OF Santos Júnior; Methodology, O Freitas Neto and PJR Albuquerque; Investigation, O Freitas Neto, PJR Albuquerque and JR Garcia; Writing - original draft, O Freitas Neto, RP Cunha and PJR Albuquerque; Writing - review \& editing, O Freitas Neto, RP Cunha, PJR Albuquerque, JR Garcia and OF Santos Júnior; Funding acquisition, PJR Albuquerque; Resources, O Freitas Neto and PJR Albuquerque; Supervision, O Freitas Neto, RP Cunha, PJR Albuquerque and OF Santos Júnior.

Editor: Pablo Andrés Muñoz Rojas.

\section{References}

Abdrabbo F.M. (1997). Misuse of soils and foundation causes disaster. In: Proceedings of the International Conference on Foundation Failures, Vol.1. Singapore. p. 121-130.

BS 8004 (1986). Code of practice for foundations. British Standards Institution.

Chung N.D, Kim D, Jo S. (2013). Settlement of piled rafts with different pile arrangement schemes via centrifuge tests. Journal of Geotechnical and Geoenvironmental Engineering; 139(10): 1690-1698.

Cordeiro A.F.B. (2007). Numerical evaluation of the reinforcement of a group of piles by the introduction of additional piles. MSc Thesis. Brasília, Brazil: University of Brasília. (in Portuguese). 
Cunha R.P, Cordeiro A.F.B, Sales M.M, Small J.C. (2007). Parametric analyses of pile groups with defective piles: Observed numerical behavior and remediation. In: Proceedings of the 10th Australia New Zealand Conference on Geomechanics, Vol.1. New Zealand. p. 454-459.

Cunha R.P, Cordeiro A.F.B, Sales M.M., Small J.C. (2010a). Parametric analyses of pile groups with defective piles: Observed numerical behavior and remediation. In: Proceedings of the 10th Australia New Zealand Conference on Geomechanics, Vol.1. New Zealand. p. 454-459.

Cunha R.P, Cordeiro A.F.B., Sales M.M. (2010b) Numerical assessment of an imperfect pile group with a defective pile in both initial and reinforced conditions. Soils and Rocks. 33(2). p. 81-93.

Décourt L. (1993). Predicted and measured behavior of non-displacement piles in residual soils. In: Van Impe WF, editor. Deep Foundations on Bored and Auger Piles (BAP II), Proceedings of the 2nd International Geotechnical Seminar on Deep Foundations on Bored and Auger Piles. Rotterdam: A.A. Balkema. p. 369-376.

Décourt L. (1995). On the load-settlement behavior of piles. Soils and Rocks. 18(2). p. 93-112.

Freitas Neto O. (2013). Experimental and numerical evaluation of piled rafts with defective piles in the tropical soil of Brazil. PhD Thesis. Brasília, Brazil. University of Brasilia. (in Portuguese).

Freitas Neto O., Cunha R.P., Santos Júnior O.F, Albuquerque P.J.R, Garcia J.R. (2014) Comparison of numerical methods for piled raft foundations. Advanced Materials Research. p. 838-841: 334-41.

Freitas, A. P. S. (2018). Piled raft behavior as foundations of wind energy aerogenerators. MSc Thesis. Natal, Brazil: Federal University of Rio Grande do Norte. (in Portuguese).

Garcia J.R. (2015). Experimental and numerical analysis of piled rafts in soil from Campinas/SP. PhD Thesis. Campinas, Brazil: State University of Campinas-SP. (in Portuguese).

Gon F.S. (2011) Geotechnical characterization through laboratory tests of a diabase soil from the region of Campinas/SP. MSC Thesis. Campinas, Brazil: State University of Campinas. (in Portuguese).

Hachich W., Falconi F.F., Saes J.L., Frota R.G.O., Carvalho C.S., Niyama S. (1998). Foundation: Theory and Practice. 2 nd edition. São Paulo: Ed. Pini. (in Portuguese).

Klingmüller O., Kirsch F. (2004). A quality and safety issue for cast-in-place: 25 years of experience with low-strain integrity testing in Germany, from scientific peculiarity to today's practice. In: DiMaggio J A, Hussein MH, editors. Current practices and future trends in deep foundations. American Society of Civil Engineers (ASCE). p. 202-221.

Kong L., Zhang L. (2004). Lateral or torsional failure modes in vertically loaded defective pile groups. In: Turner JP, Mayne PW, editors. GeoSupport 2004: Drilled shafts, micropiling, deep mixing, remedial methods, and specialty foundation systems. ASCE. p. 625-636.

Leung Y.F., Klar A., Soga K. (2010). Theoretical study on the pile length optimization of pile groups and piled rafts. Journal of Geotechnical and Geoenvironmental Engineering. 136(2): 319-330.

Makarchian M, Poulos H.G. (1994). Underpinning by piles: A numerical study. In: Proceedings of the 13th International Conference on Soil Mechanics and Foundation Engineering, Vol.4. New Delhi, . p. 1467-1470.

NBR 12131 (2006). Piles-Static load test-Method of test. Rio de Janeiro, Brazil: ABNT. (in Portuguese).

NBR 6122 (2010). Design and construction of foundations. Rio de Janeiro, Brazil: ABNT. (in Portuguese).

Novak J.L., Reese L.C., Wang S.T. (2005). Analysis of pile-raft foundations with the 3D finite element method. In: Structures Congress 2005: Metropolis and Beyond. ASCE. https://doi.org/10.1061/40753(171)93.

Omeman Z.M. (2012). Load sharing of piled-raft foundations in sand subjected to vertical loads. PhD Thesis. Montreal, Canada: Concordia University.

Petek K., Felice C.W., Holtz R.D. (2002) Capacity analysis of drilled shafts with defects. In: O'Neill M.W, Townsend F.C., editors. Deep Foundations 2002: An International Perspective on Theory, Design, Construction, and Performance. ASCE. p. 1120-1335. https://doi.org/10.1061/40601(256)80.

Poulos H.G. (1997) Behaviour of pile groups with defective piles. In: Proceedings of the 14th International Conference Soil Mechanics Foundation Engineering. Hamburg. p. 871-876. 
Poulos H.G. (2001). Piled raft foundations: Design and applications. Geotechnique; 51(2): 95-113.

Poulos H.G. (2005). Pile behavior - Consequences of geological and construction imperfections. Journal of Geotechnical and Geoenvironmental Engineering; 131(5): 538-563.

Rodriguez T.G. (2013). Geotechnical characterization of a diabase soil through SPT and CPT tests. MSc Thesis. Campinas, Brazil: State University of Campinas. (in Portuguese).

Scallet M.M. (2011). Behavior of small-diameter bored piles in the laterite and collapsible soil of the region of Campinas/SP. MSc Thesis. Campinas, Brazil: State University of Campinas. (in Portuguese).

Schulze T. (2013). Analysis of the load capacity of small diameter instrumented bored piles by semi-empirical methods. MSc Thesis. Campinas, Brazil: State University of Campinas. (in Portuguese).

Xu K. (2000) General analysis of pile foundations and application to defective piles. PhD Thesis. Sydney, Australia: University of Sydney.

Zhang L., Wong E. (2007). Centrifuge modeling of large-diameter bored pile groups with defects. Journal of Geotechnical and Geoenvironmental Engineering; 133(9): 1091-1101. 